\title{
Exploring the Determinants of Community Engagement in Social Q \& A Communities
}

\author{
Linlin Zhang1*, Yongwei Jiang² \\ ${ }^{1}$ Management School, Jinan University, Guangzhou, China \\ ${ }^{2}$ Staff of Pauli Real Estate Limited by Share Ltd., Guangzhou, China \\ Email: *alinllz@163.com
}

How to cite this paper: Zhang, L.L. and Jiang, Y.W. (2018) Exploring the Determinants of Community Engagement in Social Q \& A Communities. Journal of Service Science and Management, 11, 203-218. https://doi.org/10.4236/jssm.2018.112015

Received: March 15, 2018

Accepted: April 21, 2018

Published: April 24, 2018

Copyright ( 92018 by authors and Scientific Research Publishing Inc. This work is licensed under the Creative Commons Attribution International License (CC BY 4.0).

http://creativecommons.org/licenses/by/4.0/

\section{(c) (i) Open Access}

\begin{abstract}
Based on group identity and interpersonal bonds, this study constructs a theoretical framework to explain the influence mechanism of community engagement in social Q \& A community users. According to the data received from 402 users of social Q \& A community, this study empirically tested the proposed model. The results of structural equation modeling (SEM) showed that community identification is the antecedent of community engagement. And community identification plays a mediating role in the impact of perceived online relationship commitment on community engagement. Community prestige has a positive impact on community identification, and social presence and familiarity has a positive impact on the perceived online relationship commitment.
\end{abstract}

\section{Keywords}

Social Q \& A Community, Community Engagement, Community

Identification, Perceived Online Relationship Commitment, Attachment

\section{Introduction}

In recent years, people present a more precise and more refined demand for knowledge, and the social Q \& A communities came into being. The social Q \& A community is a knowledge service platform based on social media, which is based on users' questions, answers and discussions. Compared with the traditional Q \& A community, the social Q \& A community pays more attention to the quality of knowledge, the establishment of social relations, and the continuous participation and contribution of the users. Community engagement is the specific application of customer engagement concept in the network community. It refers to the behavior of users who are motivated by a certain motiva- 
tion and voluntarily produce other contributions other than trading behavior to the community, such as writing comments, prestige, recommendation, and help other consumers [1].

Although the social Q \& A community is developing rapidly, community operators still face severe challenges. In the quiz community with high maturity, most community users have low stickiness and low participation. Therefore, how to retain the existing users and encourage their community behavior has become a common concern in both the practice and the academia. On the one hand, the current network community is various, and the cost of network space transfer is low. If users find social Q \& A community can't meet their needs, they may stop using or transferring to another community of the same type [2]. On the other hand, community users do not have a clear obligation, and their knowledge contribution behavior is voluntary. It's this nature that makes it difficult for managers to encourage members to take knowledge of this kind of pro-social behavior [3] [4] [5]. Under this background, it's of great significance to understand the influencing factors and influencing mechanism of users' community engagement behaviors to better understand users' needs and improve service level in social Q \& A communities.

The essay attempts to develop and test a model exploring the determinants of community engagement in the context of social Q \& A communities. First, drawing on the social psychological study, we propose a research model to study and explain community engagement. Specifically, our model predicts that two mechanisms, identification and commitment, are the main drivers of community engagement. Through literature search, reading and analysis, this study combs users' community interaction behavior, group identity theory and interpersonal bonds theory. The socialized Q \& A community users are taken as the research object, and the sample data are obtained through the network questionnaire survey, and the theoretical model is tested. This research applies SPSS19.0 and AMOS17.0 statistical software to analyze the collected data. Descriptive statistical analysis, reliability test, validity test and structural equation model are used to verify the correctness of the theoretical model and hypothesis. The innovation points of this paper are as follows: firstly, cross disciplinary research is carried out. Based on the theory of group identity and interpersonal bonds, this study attempts to explore the determinants of social Q \& A community engagement, and make an important attempt for cross research in social psychology and relationship marketing. Secondly, based on the theory of group identity and interpersonal bonds, this paper explores the influencing factors of community engagement in social Q \& A communities. Finally, it expands the existing research on the socialized Q \& A communities and the user's engagement behavior.

\section{Theoretical Foundations and Research Hypotheses}

The theoretical root of customer engagement is expanded domain of relationship marketing and S-D logic, which emphasis on specific interpersonal interac- 
tion and creation experience [6]. Brodie et al. [7] put forward that customer engagement is the psychological state that customers produce when they interact with specific objects (such as brands) and create customer experience in specific service relationships. Van Doorn [1] et al. (2010) also believes that a specific interactive experience is an essential condition for customer alignment. These interactions and experiences may be generated by the effectiveness of the product or service [8], User information or content interaction [9] [10], and interpersonal interaction [7] [11]. The difference between identity and bonds is that people are integrated into a group based on different reasons, that is, people like the whole group-identity based attachment to a group, or because they like the individual in a group-bond-based attachment to individual member [12]. People with the same identity often take concerted action to maintain and improve their common identity. Based on this, this study focuses on user behavior in social $\mathrm{Q}$ \& A communities, and explores the influence of group identity and interpersonal bonds on user interaction under this context.

On the other hand, scholars generally believe that perceived online relationship commitment is an important factor affecting customer engagement [13]. The establishment of perceived online relational commitment usually relies on extensive and continuous interaction, so that individuals can reliably expect other individuals or organizations to act [14].

Although in traditional Q \& A network, users usually have no actual contact with others, but this does not mean that interaction cannot be produced. Previous studies have shown that in the e-commerce environment, social presence and familiarity are important factors for the formation of personal perceived online relationship commitment [15].

From the perspective of time dimension, this study explores how social presence and familiarity affect users' perceived online relationship commitment, and how users' perceived online relationship commitment affects community engagement. Among them, the social presence represents the psychological connection in the interaction of the user's reality, and the familiarity is formed by the experience of the past interaction.

To sum up, this paper will take users from social Q \& A communities, such as Zhihu and Guokr and so on, to explore how user attachment based on group identification and interpersonal bonds affect users. The research model is shown in Figure 1.

1) The influence of identity based attachment to a group on community engagement.

A growing number of literature on group identity points out that members will seek more personal contact with the group as the importance of identity increases [16]. In addition, good identification will enable individuals to produce the willingness to participate in the behavior to support the group [17]. Bhattracharya and Sankar Sen [18] (2003) also pointed out that corporate identity can make consumers more loyal and active in recommending new customers to 


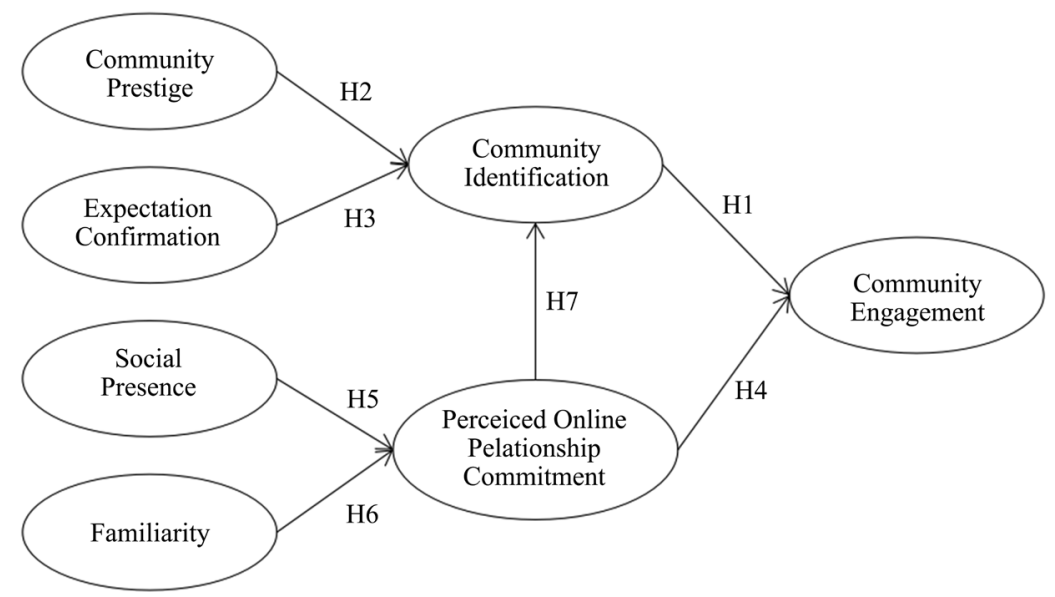

Figure 1. Research model.

businesses, and willing to spread information that is beneficial to enterprises (or avoid and resist information that is not conducive to business). Algesheimer [4] (2005) based on the empirical study of brand community, found that the customer's identity to the brand community is positively affecting the community engagement. We believe that one way to reflect or reflect this situation in the research is by supporting the community. So, we assume that:

H1: In the social Q \& A communities, community identification has a positive impact on community engagement.

Community identity depends mainly on two aspects: the community and the user. On the one hand, as a provider of community, its good prestige will lead to the generation of individual identity. Bhattacharya and Sankar Sen [18] (2003) have pointed out that organizational prestige is an important factor affecting members' identification in the research on organizational identity. The social Q \& A community is also an embodiment of the organization. On the other hand, as users of the demand side, the researchers (e.g., Hall and Schneider [19], 1972) in the field of organizational behavior show that the degree of satisfaction that individuals support for organizations to help achieve personal goals is related to identification. The more satisfaction a person gives to the organization, the higher the sense of identity is. In contrast, some studies have found that through expectations, the satisfied members will have more recognition of the group [20]. So, we assume that:

H2: In the social Q \& A communities, the perceived community prestige has a positive impact on the community identification.

H3: In the social Q \& A communities, expectation confirmation has a positive impact on community identification.

2) The influence of bond-based attachment to individual member on community engagement.

The relationship commitment reflects the inner perception of the individual's dependence on the established relationship [13]. Therefore, in the study of this article, Perceived online relationship commitment is defined as "the extent to 
which individuals believe themselves (he/she) can maintain relationships with others in the socialized Q \& A community" [21]. The higher the demand for individuals to maintain this established relationship, the stronger the attachment to the relationship will be, which is to spend more time and energy in maintaining and continuing interaction with partners. In the social Q \& A communities, participation is a way of building a close relationship, which can be regarded as a social support and a pro social behavior. In the process of maintaining the established relationship, individual users become more willing to participate in the community to help others. Community participation is also seen as a positive act. So, we assume that:

H4: In the social Q \& A communities, the perceived online relationship commitment has a positive impact on the community engagement.

The sense of social presence is defined as the extent to which the user psychologically perceiving others' existence through the media [22]. Previous studies have shown that social presence can be realized through practical or virtual interaction, and influence the pleasure of the customer to produce a feeling of psychological proximity [23]. In the socialized e-commerce, social presence promotes the development of the relationship between customers and strengthens their socialized ability. Therefore, in the social Q \& A community, the higher the user perceived social presence is, the more willing they are to participate in interaction, such as sharing information and asking questions, which is more conducive to perceive the formation of relationship commitment.

Familiarity involves the understanding and experience of consumers about when, how, and by whom [14] usually in the interaction and learning of the past [24]. Research shows that familiarity reduces the confusion and misunderstanding in the process of customer transaction [15]. It can also effectively predict the future behavior of suppliers or other individuals [25]. Therefore, in the socialized Q \& A community, familiarity may increase the confidence of the user, which leads to a higher commitment to perceived relationships. Accordingly, we propose the following hypothesis:

H5: In the social Q \& A communities, social presence has a positive impact on perceived online relationship commitment.

H6: In the social Q \& A communities, familiarity has a positive impact on perceived online relationship commitment.

3) The impact of perceived online relationship commitment on community identification.

Concern for a sense of belonging is an important factor in the formation of human thoughts [13]. That is to say, the existence of real or virtual bonds will have an impact on the way people think [26]. The community identity of individual users is influenced by the commitment of personal perception. In particular, the stronger the individual's attachment to the socialized Q \& A community, the greater the sense of belonging of the individual to the socialized Q \& A community. This leads to an increase in switching costs. In this case, the more 
users contribute to the social Q \& A community, the higher the cost of conversion to other communities, because once he or she leaves, he or she will have nothing. As a result, when a personal user has a strong attachment to other members, the user will have a strong dependence on the whole socialized Q \& A community. So, we assume:

H7: In the socialized Q \& A community, the users' perceived online relationship commitment has a positive impact on the community identification.

\section{Research Methodology}

\subsection{Measurement}

The majority of the tested scales used in our survey were adapted from the previous literature. Specifically, the scales for community engagement were adapted from Ray et al. [5] (2014). These scales captured the affective, cognitive, and pro-social characteristics that are simultaneously involved in engagement. The scales used to measure community identification are also drawn from Ray et al. [5] (2014). These scales avoided items that measured affective bonds in favor of items that reflected the definition of identification as the commonality of values, vision, and goals between respondents and their respective social Q \& A communities. To measure perceived online relationship commitment, we used scales drawn from Ma and Yuen [21] (2011) to assess individual believes about he/she can persist in a relationship with others on a social Q \& A community.

To measure the community prestige, we used scales drawn from Stokburger et al. [27] (2012) to assess users' status or esteem associated with a social Q \& A community. Additionally, measures for expectation confirmation were adapted from Bhattacherjee [28] (2001). These scales measure whether their experience with using social Q \& A community is better than their expectation.

The scales used to measure social presence were adapted from Animesh et al. [29] (2011) to assess a participant's perception of how personal, warm, intimate, sociable, or sensitive the social interactions are in the social Q \& A community. To measure familiarity, we used scales drawn from Chiu et al. [30] (2012) to assess participant's understanding and knowledge about the social Q \& A community. All items were measured using a seven-point Likert scale ranging from "strongly disagree" to "strongly agree".

\subsection{Sample and Data Collection}

The questionnaire was translated from English to Chinese and then back-translated from Chinese to English by certified professional translators to ensure the integrity of the constructs. Before deploying the main survey instrument, we invited 20 undergraduate students at a public university in China to conduct a pilot study in order to ensure that their understanding of the meaning of the items was consistent with the constructs being used in this study. Some minor modifications were made based on their feedbacks. The revised questionnaire was then used for the official online survey (Appendix). 
In order to assess the validation of the proposed model, we collected data from China social Q \& A community user using an online survey. Instead of studying users of one or two social Q \& A community, we targeted a broad set of online users who might have used many social Q \& A communities. A self-reported survey was distributed to social Q \& A community users. Only those who self-reposed as had used social Q \& A community were eligible to participate in this study. The surveys asked respondents to consider a social Q \& A community they recently visited. A total of 402 users completed the survey. The demographic details of these social Q \& A community users are described in Table 1.

Table 1. Sample demographics.

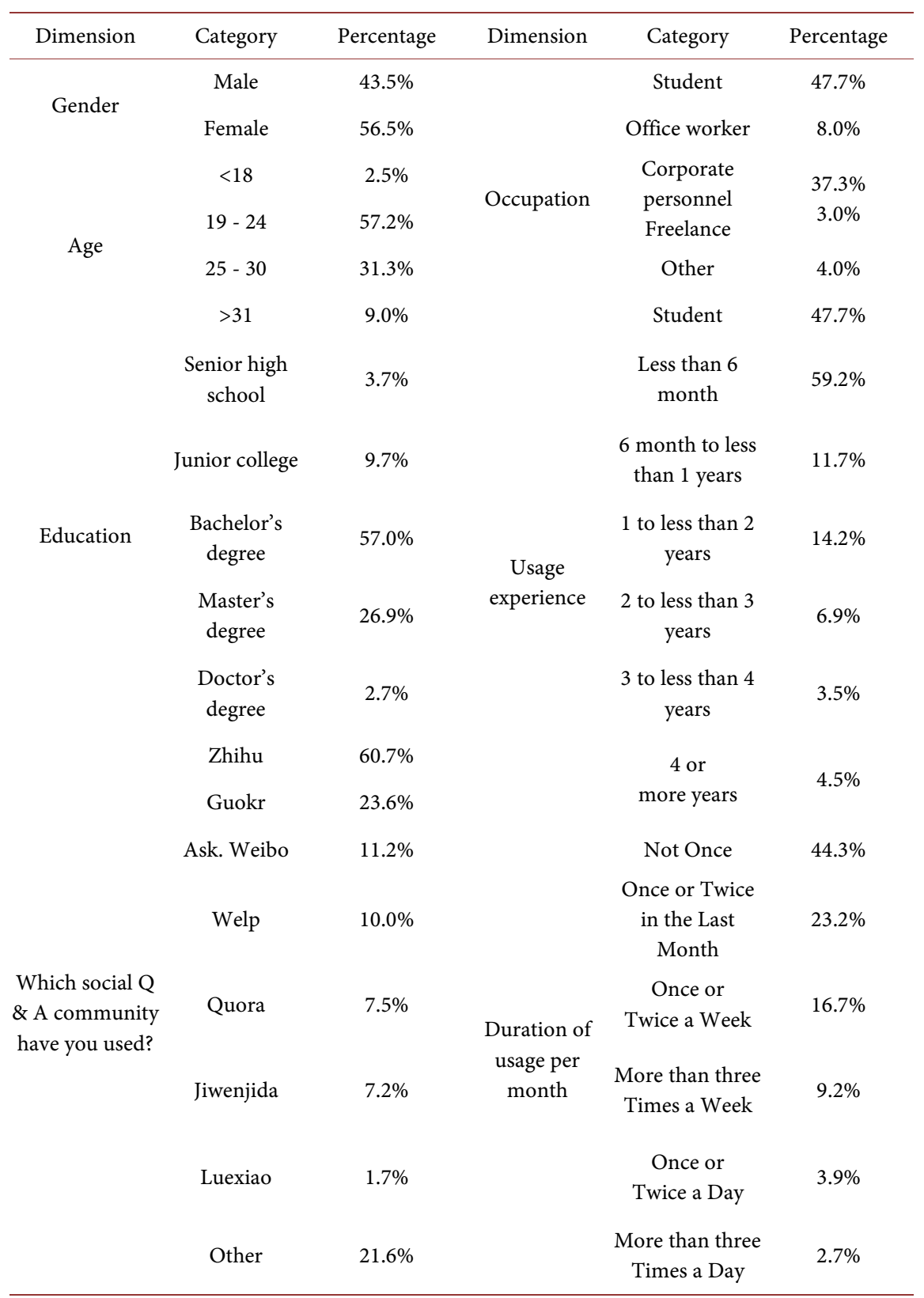




\section{Data Analysis and Discussion}

The structural equation modeling (SEM) was used to statistically test theoretical assumptions against empirical data. SEM is a multivariate technique that combines aspects of multiple regression and factor analysis to estimate a series of interrelated dependence relationships simultaneously. Consequently, we conducted our main data analysis using an AMOS 21.0, which can test confirmatory measurement, goodness-of-fit, and common method bias.

A two-step approach was used for data analysis. We firstly assessed the measurement model and then tested the structural relationships among the latent constructs. We used the two-step approach in order to establish the reliability and validity of the measures before assessing the structural relationship of the model.

\subsection{Measurement Model}

Confirmatory factor analysis (CFA) was used to assess the measurement model. One item of social presence was dropped due to the high cross loading. All fit indices meet the commonly applied thresholds (see Table 2).

We further evaluated internal consistency, convergent validity, and discriminant validity by examining the Cronbach's alpha, composite reliability, and average variance extracted (AVE) of each construct (see Table 3). Internal reliability was examined by Cronbach's alpha and composite reliability. The values of Cronbach's alpha and CR were higher than the criterion 0.70 [31], thereby justifying an adequate level of internal reliability. Convergent validity was used to ensure that theoretically related scales were highly correlated. Three criteria of convergent validity were proposed as a CR of more than 0.70, an AVE of 0.50 or above and item loadings higher than 0.70 [32]. As shown in Table 3, the CR of each construct ranges from 0.88 to 0.95 , the AVE ranges from 0.71 to 0.87 , and all the item loadings are higher than 0.70 . All of these measures meet the recommended levels.

Table 2. Fit indices of measurement model.

\begin{tabular}{cccc}
\hline Goodness of fit indices & Initial model & Revised model & Desired levels \\
\hline CMIN/DF & 2.32 & 2.22 & $<3.0$ \\
CFI & 0.97 & 0.97 & $>0.90$ \\
TLI & 0.96 & 0.97 & $>0.90$ \\
RMSEA & 0.057 & 0.055 & $<0.08$ \\
Standardized RMR & 0.035 & 0.034 & $<0.08$ \\
GFI & 0.89 & 0.91 & $>0.90$ \\
AGFI & 0.86 & 0.88 & $>0.80$ \\
No. of latent variables & 7 & 7 & \\
Total no. of items & 25 & 24 & \\
\hline
\end{tabular}

Note. CFI = comparative fit index; TLI = Tucker-Lewis index; RMSEA = root mean square error of approximation; RMR = root mean square residual; GFI = goodness-of-fit index; AGFI = adjusted GFI. 
Table 3. Confirmatory factor analysis.

\begin{tabular}{|c|c|c|c|c|c|}
\hline Latent construct & Indicator & Standard loading & Cronbach's Alpha & $\mathrm{CR}$ & AVE \\
\hline \multirow{3}{*}{$\begin{array}{l}\text { Community } \\
\text { Prestige }\end{array}$} & $\mathrm{CP} 1$ & $0.87^{* * *}$ & \multirow{3}{*}{0.89} & \multirow{3}{*}{0.89} & \multirow{3}{*}{0.73} \\
\hline & $\mathrm{CP} 2$ & $0.86^{* * *}$ & & & \\
\hline & $\mathrm{CP} 3$ & $0.84^{* * *}$ & & & \\
\hline \multirow{3}{*}{$\begin{array}{l}\text { Expectation } \\
\text { Confirmation }\end{array}$} & $\mathrm{EC} 1$ & $0.88^{* * *}$ & \multirow{3}{*}{0.90} & \multirow{3}{*}{0.90} & \multirow{3}{*}{0.76} \\
\hline & EC2 & $0.90^{* * *}$ & & & \\
\hline & EC3 & $0.83^{* * *}$ & & & \\
\hline \multirow{4}{*}{ Social Presence } & SP1 & $0.85^{* * *}$ & \multirow{4}{*}{0.93} & \multirow{4}{*}{0.93} & \multirow{4}{*}{0.76} \\
\hline & SP2 & $0.90^{* * *}$ & & & \\
\hline & SP4 & $0.90^{* * *}$ & & & \\
\hline & SP5 & $0.84^{* * *}$ & & & \\
\hline \multirow{3}{*}{ Familiarity } & FL1 & $0.91^{* * *}$ & \multirow{3}{*}{0.95} & \multirow{3}{*}{0.95} & \multirow{3}{*}{0.87} \\
\hline & FL2 & $0.95^{* * *}$ & & & \\
\hline & FL3 & $0.94^{* * *}$ & & & \\
\hline \multirow{3}{*}{$\begin{array}{l}\text { Community } \\
\text { Identification }\end{array}$} & CI1 & $0.92^{* * *}$ & \multirow{3}{*}{0.94} & \multirow{3}{*}{0.94} & \multirow{3}{*}{0.83} \\
\hline & $\mathrm{CI} 2$ & $0.91^{* * *}$ & & & \\
\hline & $\mathrm{CI} 3$ & $0.91^{* * *}$ & & & \\
\hline \multirow{5}{*}{$\begin{array}{l}\text { Perceived Online } \\
\text { Relationship } \\
\text { Commitment }\end{array}$} & $\mathrm{PC} 1$ & $0.87^{* * *}$ & \multirow{5}{*}{0.95} & \multirow{5}{*}{0.95} & \multirow{5}{*}{0.79} \\
\hline & $\mathrm{PC} 2$ & $0.92^{* * *}$ & & & \\
\hline & PC3 & $0.89^{* * *}$ & & & \\
\hline & PC4 & $0.85^{* * *}$ & & & \\
\hline & PC5 & $0.92^{* * *}$ & & & \\
\hline \multirow{3}{*}{$\begin{array}{l}\text { Community } \\
\text { Engagement }\end{array}$} & CE1 & $0.87^{* * *}$ & \multirow{3}{*}{0.87} & \multirow{3}{*}{0.88} & \multirow{3}{*}{0.71} \\
\hline & CE2 & $0.88^{* * *}$ & & & \\
\hline & CE3 & $0.78^{* * *}$ & & & \\
\hline
\end{tabular}

Discriminant validity indicates that the extent of the construct is low in correlation with other constructs. Such validity is demonstrated when the square root of AVE for the given construct is higher than the correlations between that construct and all other constructs [32]. As shown in Table 4, the square root of AVE exceeds the correlations between each construct and the other constructs, suggesting adequate discriminant validity for all constructs.

\subsection{Structural Model}

Following the establishment of the measurement model, we go forward to the structural model. The overall fit and the explanatory power of the proposed model were examined, and the results are shown in Table 5 and Figure 2. The overall goodness-of-fit (see Table 5) suggests a good fit between the structural model and the data.

Figure 2 illustrates the path coefficients and explanatory power for the structural model. Five of the seven proposed hypotheses were supported. Community identification ( $\mathrm{H} 1 ; \beta=0.66)$ had significant effects on community engagement, explaining $50 \%$ of its variance. Contrary to our expectation, perceived online relationship commitment had no statistically significant effect on community engagement (H4 was not supported). 
Table 4. Discriminant validity.

\begin{tabular}{cccccccc}
\hline & CP & EC & SP & FL & CI & PC & CE \\
\hline $\begin{array}{c}\text { Community } \\
\text { Prestige (CP) }\end{array}$ & 0.85 & & & & & \\
$\begin{array}{c}\text { Expectation } \\
\text { Confirmation (EC) }\end{array}$ & 0.74 & 0.87 & & & & & \\
$\quad$ Social & 0.74 & 0.70 & 0.87 & & & \\
$\begin{array}{c}\text { Presence (SP) } \\
\text { Familiarity (FL) }\end{array}$ & 0.69 & 0.67 & 0.56 & 0.93 & & \\
$\quad \begin{array}{c}\text { Community } \\
\text { Identification (CI) } \\
\text { Perceived Online } \\
\text { Relationship }\end{array}$ & 0.72 & 0.59 & 0.64 & 0.53 & 0.91 & \\
Commitment (PC) & 0.59 & 0.56 & 0.61 & 0.49 & 0.83 & 0.89 & \\
$\begin{array}{c}\text { Community } \\
\text { Engagement (CE) }\end{array}$ & 0.75 & 0.67 & 0.76 & 0.59 & 0.68 & 0.61 & 0.84 \\
\hline
\end{tabular}

Table 5. Fit indices of structure model.

\begin{tabular}{ccc}
\hline Goodness of fit indices & Structure model & Desired levels \\
\hline CMIN/DF & 2.76 & $<3.0$ \\
CFI & 0.96 & $>0.90$ \\
TLI & 0.95 & $>0.90$ \\
RMSEA & 0.066 & $<0.08$ \\
Standardized RMR & 0.08 & $<0.08$ \\
GFI & 0.89 & $>0.90$ \\
AGFI & 0.86 & $>0.80$ \\
No. of latent variables & 7 & \\
Total no. of items & 24 & \\
\hline
\end{tabular}

Note. CFI = comparative fit index; TLI = Tucker-Lewis index; RMSEA = root mean square error of approximation; $\mathrm{RMR}$ = rootmean square residual; GFI = goodness-of-fit index; AGFI = adjusted GFI.



Figure 2. Structural model results.

The results also show that perceived online relationship commitment $(\beta=$ $0.63)$ and community prestige $(\beta=0.39)$ had statistically significant effects on 
community identification, explaining $78 \%$ of its variance. $\mathrm{H} 2, \mathrm{H} 7$ were thus supported. However, expectation confirmation had no statistically significant effects on community identification, contrary to the relationship proposed in H3. Finally, social presence $(\beta=0.50)$ and familiarity $(\beta=0.22)$ had significant effects on perceived online relationship commitment, explaining $42 \%$ of its variance; $\mathrm{H} 5$ and $\mathrm{H} 6$ were also supported.

The path coefficient between the latent variables is significant or not, which can be judged by T test and $P$ value. When T $>1.96$ or $P<0.05$, the path coefficient can be determined to be significant. The hypothesis test results, as shown in Table 6, are accepted in all hypotheses of this study, except that $\mathrm{H} 3$ and $\mathrm{H} 4$ are not accepted, and the other 5 hypotheses are accepted.

\section{Conclusions}

This study aims to provide a research model to reveal the determinants of community engagement in social Q \& A community. The results lend support to five of the seven proposed links. The research model accounted for $50 \%$ of the variance in community engagement. While community identification significantly influenced community engagement, perceived online relationship commitment had no statistically significant effect on community engagement. The effect of perceived online relationship commitment on community engagement was mediated by community identification.

Moreover, we found that community prestige and perceived online relationship commitment collectively explained $78 \%$ of the variance in community identification. Contrary to our hypothesis, expectation confirmation did not significantly impact community identification.

Table 6. Hypothesis test results.

\begin{tabular}{|c|c|c|c|c|c|}
\hline Number & Hypothesis & $\begin{array}{c}\text { Path } \\
\text { coefficient }\end{array}$ & $\begin{array}{c}\mathrm{T} \\
\text { Statistics }\end{array}$ & $P$ Values & Result \\
\hline $\mathrm{H} 1$ & $\begin{array}{l}\text { community identification has a positive impact } \\
\text { on community engagement. }\end{array}$ & 0.66 & 7.32 & 0.000 & accept \\
\hline $\mathrm{H} 2$ & $\begin{array}{l}\text { the perceived community prestige has a positive } \\
\text { impact on the community identification. }\end{array}$ & 0.39 & 7.22 & 0.000 & accept \\
\hline $\mathrm{H} 3$ & $\begin{array}{l}\text { expectation confirmation has a positive impact } \\
\text { on community identification. }\end{array}$ & -0.02 & -0.42 & 0.672 & refuse \\
\hline $\mathrm{H} 4$ & $\begin{array}{l}\text { the perceived online relationship commitment } \\
\text { has a positive impact on the community } \\
\text { engagement. }\end{array}$ & 0.06 & 0.66 & 0.512 & refuse \\
\hline H5 & $\begin{array}{l}\text { social presence has a positive impact on } \\
\text { perceived online relationship commitment. }\end{array}$ & 0.50 & 8.99 & 0.000 & accept \\
\hline H6 & $\begin{array}{l}\text { familiarity has a positive impact on perceived } \\
\text { online relationship commitment. }\end{array}$ & 0.22 & 4.27 & 0.000 & accept \\
\hline $\mathrm{H} 7$ & $\begin{array}{l}\text { perceived online relationship commitment has a } \\
\text { positive impact on the community } \\
\text { identification. }\end{array}$ & 0.63 & 14.90 & 0.000 & accept \\
\hline
\end{tabular}


In addition, interaction is the foundation of the relationship commitment. In particular, social presence and familiarity collectively explained $42 \%$ of the variance in perceived online relationship commitment. Moreover, we found that social presence $(\beta=0.50)$ has a stronger power than familiarity $(\beta=0.22)$ in explaining perceived online relationship commitment.

In conclusion, this study shows that community identification is the antecedent variable of community engagement, and community identification completely mediates the impact of perceived online relationship commitment on community engagement. Perceived community prestige is an important factor affecting community identification, and social existence and familiarity will positively affect the perceived online relationship commitment.

\section{References}

[1] Van Doorn, J., Lemon, K.N., Mittal, V., et al. (2010) Customer Engagement Behavior: Theoretical Foundations and Research Directions. Journal of Service Research, 13, 253-266. https://doi.org/10.1177/1094670510375599

[2] Zheng, Y.M., Zhao, K. and Stylianou, A. (2013) The Impacts of Information Quality and System Quality on Users' Continuance Intention in Information-Exchange Virtual Communities: An Empirical Investigation. Decision Support Systems, 56, 513-524. https://doi.org/10.1016/j.dss.2012.11.008

[3] McAlexander, J.H., Schouten, J.W. and Koenig, H.F. (2002) Building Brand Community. Journal of Marketing, 66, 38-54. https://doi.org/10.1509/jmkg.66.1.38.18451

[4] Algesheimer, R., Dholakia, U.M. and Herrmann, A. (2005) The Social Influence of Brand Community: Evidence from European Car Clubs. Journal of Marketing, 69, 19-34. https://doi.org/10.1509/jmkg.69.3.19.66363

[5] Ray, S., Kim, S.S. and Morris, J.G. (2014) The Central Role of Engagement in Online Communities. Information Systems Research, 25, 528-546. https://doi.org/10.1287/isre.2014.0525

[6] Vargo, S.L. and Lusch, R.F. (2008) Service-Dominant Logic: Continuing the Evolution. Journal of the Academy of Marketing Science, 36, 1-10. https://doi.org/10.1007/s11747-007-0069-6

[7] Brodie, R.J., Hollebeek, L.D., Juric, B., et al. (2011) Customer Engagement: Conceptual Domain, Fundamental Propositions, and Implications for Research. Journal of Service Research, 14, 252-271. https://doi.org/10.1177/1094670511411703

[8] Caru, A. and Cova, B. (2007) Consuming Experiences: An Introduction. Consuming Experiences, Routledge, London, 3-16.

[9] Cho, C.H. and Leckenby, J.D. (1997) Internet-Related Programming Technology and Advertising. Proceedings of the Conference-American Academy of Advertising, 69-79.

[10] Massey, B.L. and Levy, M.R. (1999) Interactivity, Online Journalism, and English-Language Web Newspapers in Asia. Journalism \& Mass Communication Quarterly, 76, 138-151. https://doi.org/10.1177/107769909907600110

[11] Haeckel, S.H. (1998) About the Nature and Future of Interactive Marketing. Journal of Interactive Marketing, 12, 63-71.

https://doi.org/10.1002/(SICI)1520-6653(199824)12:1\%3C63::AID-DIR8\%3E3.0.CO $\underline{; 2-\mathrm{C}}$ 
[12] Back, K.W. (1951) Influence through Social Communication. Journal of Abnormal Psychology, 46, 9. https://doi.org/10.1037/h0058629

[13] Ma, W.W.K., Yuen, A.H.K., Park, J., et al. (2015) New Media, Knowledge Practices and Multiliteracies. Springer, Singapore. https://doi.org/10.1007/978-981-287-209-8

[14] Luhmann, N., Poggi, G., Burns, T., et al. (1979) Trust and Power: Two Works. U-M-I Out of Print Books on Demand.

[15] Gefen, D. (2000) E-Commerce: The Role of Familiarity and Trust. Omega, 28, 725-737. https://doi.org/10.1016/S0305-0483(00)00021-9

[16] Mael, F. and Ashforth, B.E. (1992) Alumni and Their Alma Mater: A Partial Test of the Reformulated Model of Organizational Identification. Journal of Organizational Behavior, 13, 103-123. https://doi.org/10.1002/job.4030130202

[17] Fisher, R.J. and Wakefield, K. (1998) Factors Leading to Group Identification: A Field Study of Winners and Losers. Psychology \& Marketing, 15, 23-40. https://doi.org/10.1002/(SICI)1520-6793(199801)15:1<23::AID-MAR3>3.0.CO;2-P

[18] Bhattacharya, C.B. and Sen, S. (2003) Consumer-Company Identification: A Framework for Understanding Consumers' Relationships with Companies. Journal of Marketing, 67, 76-88.

[19] Hall, D.T. and Schneider, B. (1972) Correlates of Organizational Identification as a Function of Career Pattern and Organizational Type. Administrative Science Quarterly, 17, 340-350. https://doi.org/10.2307/2392147

[20] Oliver, R.L. and Swan, J.E. (1989) Equity and Disconfirmation Perceptions as Influences on Merchant and Product Satisfaction. Journal of Consumer Research, 16, 372-383. https://doi.org/10.1086/209223

[21] Ma, W.W.K. and Yuen, A.H.K. (2011) Understanding Online Knowledge Sharing: An Interpersonal Relationship Perspective. Computers \& Education, 56, 210-219. https://doi.org/10.1016/j.compedu.2010.08.004

[22] Fulk, J., et al. (1987) A Social Information Processing Model of Media Use in Organizations. Communication Research, 14, 529-552. https://doi.org/10.1177/009365087014005005

[23] Hassanein, K. and Head, M. (2005) The Impact of Infusing Social Presence in the Web Interface: An Investigation across Product Types. International Journal of Electronic Commerce, 10, 31-55. https://doi.org/10.2753/JEC1086-4415100202

[24] Gefen, D., Karahanna, E. and Straub, D.W. (2003) Inexperience and Experience with Online Stores: The Importance of TAM and Trust. IEEE Transactions on Engineering Management, 50, 307-321. https://doi.org/10.1109/TEM.2003.817277

[25] Doney, P.M. and Cannon, J.P. (1997) An Examination of the Nature of Trust in Buyer-Seller Relationships. Journal of Marketing, 61, 35-51. https://doi.org/10.2307/1251829

[26] Baumeister, R.F. and Leary, M.R. (1995) The Need to Belong: Desire for Interpersonal Attachments as a Fundamental Human Motivation. Psychological Bulletin, 117, 497-529. https://doi.org/10.1037/0033-2909.117.3.497

[27] Stokburger-Sauer, N., Ratneshwar, S. and Sen, S. (2012) Drivers of Consumer-Brand Identification. International Journal of Research in Marketing, 29, 406-418. https://doi.org/10.1016/j.ijresmar.2012.06.001

[28] Bhattacherjee, A. (2001) Understanding Information Systems Continuance: An Expectation-Confirmation Model. MIS Quarterly, 25, 351-370. https://doi.org/10.2307/3250921

[29] Animesh, A., Pinsonneault, A., Yang, S.B., et al. (2011) An Odyssey into Virtual 
Worlds: Exploring the Impacts of Technological and Spatial Environments on Intention to Purchase Virtual Products. MIS Quarterly, 35, 789-810.

https://doi.org/10.2307/23042809

[30] Chiu, C.M., Hsu, M.H., Lai, H., et al. (2012) Re-Examining the Influence of Trust on Online Repeat Purchase Intention: The Moderating Role of Habit and Its Antecedents. Decision Support Systems, 53, 835-845.

https://doi.org/10.1016/j.dss.2012.05.021

[31] Nunnally, J.C. and Bernstein, I.H. (1994) Validity. Psychometric Theory. McGraw-Hill, New York, 99-132.

[32] Fornell, C. and Larcker, D.F. (1981) Evaluating Structural Equation Models with Unobservable Variables and Measurement Error. Journal of Marketing Research, 18, 39-50. https://doi.org/10.2307/3151312 


\section{Appendix}

Questionnaire of community engagement in social question and answer communities.

Dear Lady/Mr:

Hello! I am a master's graduate student at the School of management, Jinan University. At present, a survey is being carried out on the factors that affect the community engagement in social Q \& A communities. We sincerely invite you to take 5 - 10 minutes in your busy schedule to fill out the following questionnaires. All the survey data will be used for academic research and strictly confidential. The results will only show comprehensive information, and will not involve any personal information. Please choose the most suitable answer according to the actual situation of using the social Q \& A communities. Thank you for your participation!

(Description: the social Q \& A community is a knowledge service platform based on social media, which is based on users' questions, answers and discussions. It has both the professionalism and openness of the encyclopedia web sites, the interactivity of question and answer websites and the increase of social service functions. For example, Quora, Zhihu, Guokr, Ask.Weibo, Welp, Jiwenjida, Luexiao, and so on.)

Part 1: Basic information. Please choose the right answer according to your actual situation.

1. Your sex:

1) male; 2) female

2. Your age:

1) under age 18;2) 19 - 24 years old;3) 25 - 30 years old; 4) 31 - 35 years old; 5) 36 - 40 years old; 6) 41 - 45 years old; 7) 46 - 50 years old; 8) More than 50 years old

3. Your education level is:

1) high school and below; 2) college; 3 ) undergraduate; 4) Master; 5) doctor and above

4. Your occupation is:

1) the students in the school; 2) the Workers in the party and government institutions and institutions; 3) Enterprise staff; 4) the freelance; 5) other (please fill in)

5. Which social Q \& A community(s) have you used?

1) Quora; 2) Zhihu; 3) Guokr; 4) Luexiao; 5) Welp; 6) Jiwenjida; 7) Ask.Weibo; 8) other (please fill in)

6. How long has it been for you to use the social Q \& A communities:

1) under 6 months; 2) 6 months to 1 years; 3) 1 to 2 years; 4) 2 to 3 years; 5) 3 to 4 years; 6) 4 years or more

7. How often do you use the social Q \& A communities over the past month:

1) none; 2) 1 to 2 times; 3) 1 to 2 times a week; 4) more than 3 times a week; 5) 1 to 2 times a day; 6) more than 3 times a day

Please answer the following contents according to the actual use of the social Q \& A community that you most often use. Choose a most suitable answer you think is the most appropriate. Among them, " 1 " represents "totally disagree”, " 2 " represents "Disagree”, “3” represents "A little disagree”, “4” represents “Uncertain”, “ ” represents "A little agree”, “6”represents “Agree”, “7”represents 'totally agree”, 
Part 2: Social Q \& A community users' perceived benefits.

$\begin{array}{lllllll}1 & 2 & 3 & 4 & 5 & 6 & 7\end{array}$

CP1: The social Q \& A community has a high prestige.

CP2: The social Q \& A community is one of the best quiz communities.

CP3: The social Q \& A community is an excellent, high-quality

$\mathrm{Q} \&$ A community.

EC1: I used the social Q \& A community to experience better than I expected.

EC2: The social Q \& A community provides a better level of service than I expected.

EC3: As a whole, my expectations for the social Q \& A community have basically been achieved.

When using a social Q \& A community, the interaction with other members is...

SP1: interpersonal.

SP2: warm.

SP3: close.

SP4: humanized.

SP5: rich in emotion.

FL1: I'm very familiar with the social Q \& A community.

FL2: I'm very familiar with the process of asking the social Q \&

A community to search for knowledge.

FL3: I'm very familiar with how to get knowledge in the social Q

\& A community.

Part 3: The emotional attitude of the user to the social Q \& A community.

$\begin{array}{lllllll}1 & 2 & 3 & 4 & 5 & 6 & 7\end{array}$

CI1: The social Q \& A community has a common vision for me.

CI2: The social Q \& A community has a common goal with me.

CI3: The social Q \& A community has shared values with me.

PORC1: I stick to the social Q \& A community to maintain the relationship with the other members of the community.

PORC2: I hope to maintain a long-term relationship with the other members of the community through the social Q \& A community.

PORC3: I have a strong connection with the other members of the community through the use of the social Q \& A community.

PORC4: In the social Q \& A community, I would be very upset if the relationship with other members of the community came to an end.

PORC5: Through the use of the social Q \& A community, I seek to maintain a long-term relationship with other members of the community

CCE1: I would like to participate in the social Q \& A community's activities, because participation makes me feel better.

CCE2: I would like to participate in the social Q \& A community's activities, because participation enables me to help other members.

CCE3: I am willing to participate in the social Q \& A community, because participation enables me to achieve personal goals. 